\title{
Research on Necessities and Strategies of Whole Process Cost Control of Urban Construction Project
}

\author{
Jinxin Hao \\ School of Economics and Management, Tianjin Chengjian University, Tianjin, 300384, China
}

Keywords: urban construction; engineering cost; cost control; whole process

\begin{abstract}
The whole process control of the project cost is more and more applied in the construction of the project. The design, construction and acceptance stages of the project are the most important parts of the whole process control of the project cost. There are many noticeable points in every link of urban construction project. The scientific and reasonable grasp of the points can successfully control the whole process of urban construction project cost. This paper analyzes the necessities and strategies of the whole process control of the construction cost of urban construction project to provide some references for relevant researchers.
\end{abstract}

\section{Introduction}

The urban construction project is the essential material basis to ensure the economic development of the city and the normal operation of the city [1]. Many construction projects are under tense construction, and many of them are waiting for approval and construction. However, with this heavy task is not commensurate with the work mode, the construction project cost control is still very backward, belong to the extensive mode of control, this control mode is mainly manifested in easily because of carelessness delayed the project progress, it is difficult to accurately control the cost, construction accidents. Any construction enterprise is trying to maximize its own economic benefits. For construction enterprises, its control is to use scientific and reasonable control means to minimize the cost and maximize the economic profits. Therefore, more and more enterprises have formed the management strategy of strengthening cost control, reducing unnecessary expenditure and increasing utilization efficiency. Many construction projects in the process of construction, cost control is not in place, resulting in relatively high cost of construction, has a certain impact on the economic benefits of enterprises, and is not conducive to the sustainable development of construction enterprises. Cost control is a work that should be further studied and emphasized on rationality and effectiveness. Whether a project can proceed smoothly depends largely on whether the cost control of the project is in place. Therefore, without a scientific and reasonable and complete work plan, it is impossible to coordinate the changes within the work and will also take a lot of detours in the work, which will lead to the extension of the duration and cause the enterprises to suffer unnecessary losses. Its cost control is based on the actual situation of the project, which shortens the duration of the project and saves the rationalization of resources. It is a more scientific and more progressive embodiment [2].

\section{Necessities of Whole Process Cost Control of Urban Construction Project}

\subsection{Necessities in Design Stage.}

At present, the technology and economy of urban construction project design unit of our country most in-depth analysis is not enough, in most of the design of light weight technology economy, designers seem only to design urban construction project shall be responsible for the quality of urban construction, the project cost is not too concerned about, so that no optimization design by the method, the preparation of preliminary design and budget to control the total cost. The quality and depth of urban construction engineering drawings are not enough. The amount of urban construction works 
miscalculation and missing calculation in urban construction quantity list also cause the increase of temporary assessment projects, which makes the quality of bidding work difficult to guarantee, and therefore cannot effectively control the cost of urban construction projects. We should carry on the quota design, according to the approved design task book and the investment estimate and control the design of the construction drawing in accordance with the initial overall budget of the preliminary design. The quota design should not be considered to save the investment blindly, should respect the reality, and pay attention to the optimization design while implementing the quota design. At this stage, focus on the project cost management is to actively participate in the decisions of the preparatory work before, to do this work, must invest a lot of manpower, financial resources, material resources and time, and do the feasibility study, the project cost can be combined with financial department or preparation department and other relevant departments as accurately as possible to calculate the cost of the whole process including land costs, fees, pre project cost, cost of capital and management costs may occur in construction projects. The estimated investment is as comprehensive as possible. We should take full account of various factors that may affect the engineering cost during the construction period and do well in the economic evaluation of the project to make the investment estimate play a real role in controlling the investment of the project. We can effectively control the cost in the design phase with the design of the limit of liability and avoid the large change project caused by the design error [3].

\subsection{Necessities in Construction Stage.}

In the stage of construction project cost, each link is not only the individual, but need to be connected integrated system, but in the actual project put into production stage, respectively by each unit is responsible for the completion of the specific implementation, each link is between unrelated existence. In this way, all unit's lack communication and cannot solve the related financial problems in time. The whole system is very chaotic, which adds difficulties to the smooth implementation of the whole process of cost management. The supervision unit must exert his power of strong supervision of construction engineering, well concealed urban construction project acceptance work, for each visa and design change according to the correct analysis of the effective contract and liability issues, therefore causes the cost control of the volume and price of the good. A series of management measures for design change, new projects and visa projects should be worked out before construction projects are built, so that every cost change must be verified by supervision units, design units and owners. The design in the construction process of change and new projects, such as professional visa cost in the cost control, can carry out cost analysis in a timely manner, to the owners of scientific construction, investment management, investment projects to control, to avoid the phenomenon of post check, get ready for the day after the settlement. In the actual construction phase of the project, there are usually several construction units involved. The cost of the project in the early stage becomes the obstacle to the progress of each unit. Therefore, the construction side and cannot be completely in accordance with the preliminary planning of the construction, and according to their own experience any changes to the original design, shoddy work, cause the whole process control of construction cost of the process spec, increases in disguise economic losses [4].

\subsection{Necessities in Acceptance Stage.}

The amount of urban construction works is the way of settlement stipulated in the contract of urban construction. There are many kinds of settlement methods, such as construction drawings, comprehensive unit price, contract fees, and actual settlement of urban construction projects. Different calculation methods will cause great difference. Therefore, the settlement personnel must be combined with the tender documents, tender list and tender clarification, the terms of the contract price, the price dispute must be handled according to the mode of the contract. The cost personnel should first confirm the validity of the data before the cost of the audit is audited. For example, the original design unit shall be issued by the design change notification of design changes and modify drawings, design personnel must be signed and stamped by the construction unit, and agreed to be included in the settlement visa visa is valid; visa; check hidden construction acceptance records of 
more than two people have signed the formalities must be complete, is consistent with the construction drawings the amount of. In the examination and acceptance stage of the construction project completion, the project is close to the end. The main problem is the acceptance of the quality of the project by the contractor. If the contract between the employer and the contractor is not stated on some issues, the two sides will shirk their responsibilities on the problem itself. Later problems cannot be solved. The time limit for the construction will be delayed, and the cost of the construction cost will increase, which will make the cost control at this stage affected. Completion of the project marks the completion of the project and reflects the actual cost of the whole construction project. The cost control at this stage is mainly to control the audit price of the completion settlement. According to the design phase of the contract signing, design bidding documents and construction drawings and other strict audit projects, participate in the audit personnel are the main units involved in the project, the owners and industry experts, the actual work, the participants should be familiar with the respective project report, the audit experts according to the actual project to ensure the accuracy of Engineering cost.

\section{Strategies of Whole Process Cost Control of Urban Construction Project}

\subsection{Strategies in Design Stage.}

The design stage is the most critical stage of the whole process control of the construction cost. The design stage is mainly to control the design budget, which cannot exceed the estimated value of the project, and the design project budget cannot exceed the design budget. The optimization and modification of the scheme are mainly the optimization design of value engineering and the design of the minimum cost method for equipment selection. Only when the design plan is within the design budget can the next step be taken. Otherwise, it is necessary to revise the plan or reconsider the design budgetary estimate, and the design of the construction drawing also needs to meet the budget of the construction drawing. In the process of bidding for construction, the price of the project should be controlled not more than the budget of the construction chart and the bid price. At the same time, the key to the cost control of the design phase is to deal with the relationship between technology and economy. The design of the same project can take a variety of practical operation plans. Different implementation plans will involve various economic budget analysis. Under the condition of satisfying the engineering quality, we should minimize the cost and save money as far as possible. On the design stage after the bidding period, commercial tender is mainly to provide reasonable budget for technical design, to strictly control the management of tender writing staff, ensure that the investment funds do not exceed the budget, the preparation of the tender to repeatedly explore the specific content, quality assurance. In the final evaluation and calibration process, the most satisfied cooperation units are determined. The design stage is the most important link in the whole process control of project cost, and we must strictly control every step to control the loss of engineering cost in the lowest range. At this stage, the owner's emphasis on project cost management is to actively participate in the preparatory work before project decision making. To do well in this area, we must invest a lot of manpower, financial resources, material resources and time, and do a good job in feasibility study.

\subsection{Strategies in Construction Stage.}

The project entered the construction phase, the multi-unit sub participation, at this time a large amount of capital investment in actual production, the most likely to cause a waste of money, the cost control of the stage is the main control to temporarily change the pre-design and economic visa settlement price in the tender reserve range. During the construction period, we must strictly eliminate the behavior of Jerry building, strengthen the management of the construction process, do well in the cost control and manage well the funds at this stage, to ensure the efficiency of investment. Reasonable use of funds in engineering is value for money. In the process of engineering construction, material cost accounts for a large proportion, about seventy percent of the total price of the total price. 
Therefore, the price of the material has a great influence on the cost of the project, and the strict control of the material price is an effective means to reduce the cost. Especially in the complex construction project construction process, there will be many unpredictable in the bidding stage of new materials and new technologies or new projects, at the same time in the bidding stage because the design is not perfect, some tentative ways into the materials used in the contract price, resulting in great difficulty to do this part of the cost control work cost control should be based on the construction contract agreed to make a reasonable adjustment to exceed the risk coefficient of new materials; bill increased material bidding in the construction process of the material or tentative price consultation; the new materials, new technologies, new projects with construction process in a reasonable way to determine the comprehensive unit price; strict cost audit of other related to the project construction, rework, sporadic rectification project. The design change, the technical approval list and the spot visa matters are analyzed in combination with technology and economy. The dynamic analysis report is provided to the construction unit through the comparison of the engineering volume and the cost increase, and the cost control target is adjusted accordingly.

\subsection{Strategies in Acceptance Stage.}

Urban construction projects, construction industry because of its large size and participate in the construction of many units, staggered, construction process interface division complex, so the interface division of the organization design, design changes and other technical and economic data of construction settlement audit data audit and the construction unit is the focus of the settlement audit. In the stage of settlement audit, we should focus on reviewing the determination of new projects, temporary or newly added materials in the construction process. We should carefully review the work according to the construction contract, supplementary agreement and relevant documents of the state and industry. In engineering construction projects, project claims become the most commonly used means for contractors to obtain projects outside the contract. Currently, the more popular way of contracting is low price and high claim. For the control of engineering cost, reasonable treatment of engineering claim is important content of project cost completion settlement stage of cost control, should be in accordance with the "claim must be based on the contract, reasonable treatment claims, strengthen the active control, reduce the engineering claim" principle, carries on the analysis according to the nature and claim events, provide reasonable calculation of the claim amount to the construction unit, construction unit and finally to assist the contractor to carry out negotiations and reach an agreement. Completion of the project marks the completion of the project and reflects the actual cost of the whole construction project. The cost control at this stage is mainly to control the audit price of the completion settlement. According to the contract signed at the design stage, the bidding documents, construction drawings and other strict audit items, people who participate in the audit mainly consist of various project participants, owners and experts in the industry. The participants should be familiar with the actual work of their respective projects and report them in a real way. The audit experts of urban construction projects should ensure the accuracy of the cost of the project according to the actual project.

\section{Conclusion}

The whole process control of urban construction project cost is the essence of the use of science and technology and legal means, to take effective measures in engineering cost control in the design phase. The implementation of the whole process of dynamic management will eventually produce the maximum economic and social benefits.

\section{References}

[1] Zhang Weiying. Discussion on The Whole Process Control of Cost in Building Engineering [J]. Engineering and Technological Research, 2018(2): 198-199.

[2] Liu Ping. Analysis on the Cost Control of the Whole Process of Urban Rail Transit Construction 
[J]. Value Engineering, 2018(8): 98-99.

[3] Huang Ying, Guo Yongshu. A brief analysis of the whole process control point of construction project cost [J]. Tendering and Bidding, 2018, 6(1): 43-45.

[4] Wang Liyong. Analyses of Urban Rail Transit Construction Cost Index [J]. Railway Engineering Technology and Economy, 2014, 29(3): 18-22. 